\title{
Risk Factors of Non-Communicable Diseases among Higher Secondary School Students in Selected Districts of India
}

\author{
R. Sogarwal ${ }^{1, *}$, D. Bachani ${ }^{2}$, Bharath Kumar ${ }^{3}$, Sanjay Gupta ${ }^{4}$ \\ ${ }^{1}$ Ex-National Programme Officer-NPCDCS, New Delhi, India \\ ${ }^{2}$ Department of Community Medicine, Lady Hardinge Medical College, New Delhi, India \\ ${ }^{3} \mathrm{PhD}$ Scholar, Gokhale Institute of Politics and Economics, Pune, Maharashtra, India \\ ${ }^{4}$ National Institute of Health and Family Welfare, New Delhi, India \\ *Corresponding author: ruchi.dr@gmail.com
}

Received December 12, 2013; Revised January 08, 2014; Accepted January 17, 2014

\begin{abstract}
Background: Tobacco and harmful use of alcohol are two commonest modifiable risk factors leading to Non Communicable Disease. Tobacco and alcohol use during adolescence have potential long term health consequences and a possibility of future addiction. The present study aims to determine the prevalence of tobacco and alcohol use among school children in selected districts of India. Methods: A cross-sectional study was conducted among 4339 students (boys: 2587; girls: 1752) of 10-19 year sage group. Data were collected through a pre-tested questionnaire using the face-to-face interview method. Bivariate and multivariate analysis was done to determine the association between socio-demographic variables and tobacco and alcohol consumption. Results: The study showed that, overall the prevalence of tobacco use in any form is higher (31.5\%) compared to the use of alcohol (7.9\%) among the study subjects. 29\% of the students do not have knowledge about the health concerns of alcohol use while $22 \%$ of students do not have knowledge about the health concerns of cigarette smoking. Significant association was found between the use of tobacco/alcohol with age, family/friends habit of tobacco/alcohol use and duration of watching television. Conclusion: Health education and knowledge about common risk factors of NCD need to be promoted among the higher secondary students. A broader and more comprehensive school based education strategy and a family based approach would be critical to prevent such unhealthy practices. Policy and its implementation on restricting availability of tobacco and unhealthy diets in and around schools will be an important step to prevent incidence of NCDs.
\end{abstract}

Keywords: tobacco, alcohol, chronic disease, India

Cite This Article: R. Sogarwal, D. Bachani, Bharath Kumar, and Sanjay Gupta, "Risk Factors of NonCommunicable Diseases among Higher Secondary School Students in Selected Districts of India." American Journal of Public Health Research, vol. 2, no. 1 (2014): 16-20. doi: 10.12691/ajphr-2-1-4.

\section{Introduction}

Non-Communicable Diseases (NCDs) like Coronary Heart Diseases, Hypertension, Diabetes, Cancer and Chronic Obstructive Pulmonary Disease are on the rise globally [1] and in India [2]. Of all the risk factors of NCDs, tobacco and alcohol are two leading modifiable factors. Prevention and cessation remain the only effective public health measures to reduce the harmful effects of smoking and alcohol use. Evidence indicates that policies and programmes focusing on reducing the burden of the common risk factors are likely to make a substantial impact onmitigating the mortality and morbidity due to NCDs [3].

In 2010, Government of India has launched National Programme for Prevention and Control of Cancer, Diabetes, Cardio-vascular Diseases and Stroke (NPCDCS) aimed to cover 100 districts across 21 states [4]. One of the important components of the programme is to conduct periodically NCD Risk Factor Survey to assess the prevalence of risk factors over-time. The World Health Organization (WHO) has recommended surveillance of common risk factors with the "STEP wise" approach, which uses standardized instruments and protocols for collecting, analyzing and monitoring trends for risk factors within and across countries [5] Thus, STEPS approach focuses on the collection of data on key risk factors of major NCDs at regular intervals in order to design communitybased interventions targeted at the reduction of these risk factors and monitoring the results of such interventions.

The World Health Organization has already warned of increasing NCDs among adolescents as a major public health problem. The importance of this age group also lies in the fact that many serious diseases in adulthood have their roots in adolescence. A few countries such as Indonesia [6] and Vietnam [7] have reported risk factors for NCDs using the WHO STEPS methodology. A few studies have also been conducted in India on tobacco 
consumption among school children, and fewer still on the use of alcohol and the awareness among them regarding their harmful effects [8-13]. Habits of family members, "Enjoyment" and "Curiosity" were found to have the major influence in their decision to use a substance $[14,15,16]$.

The objective of the paper is to assess the prevalence of tobacco and alcohol use among the students of higher secondary schools in selected districts located in different regions of the country. In addition, analyze the factors contributing to the tobacco and alcohol use among the study population. This would provide strategic direction in developing appropriate school based intervention for health promotion focusing on healthy lifestyle.

\section{Material and Methods}

This study was part of a multi-site study in India conducted with the support of WHO, aimed as a pilot for setting up national level NCD risk factor surveillance mechanisms among school children using the STEPS method [5]. The study was undertaken during July to December 2011 covering higher secondary school children in classes 8 to 10 in selected districts of India. The five district (states) covered are Nainital (Uttrakhand), Wardha (Maharashtra), Thrissur (Kerala), Ratlam (Madhya Pradesh) and Nellore (Andhra Pradesh) of India. In each district, six schools (rural-four, urban-two; Government-five, Private-one) were selected through stratified random sampling.

Keeping in view the anticipated prevalence of 5 percent (5\% tobacco use amongst school children) [17], a confidence interval of 90 percent, relative precision of 15 percent, with a design effect of 2 and the non-response rate of 10 percent, a total sample size of 1000 children per district was calculated. In each identified school, 100-200 children were expected to be enrolled for the surveillance. A total of 4339 students comprising of 2587 boys and 1752 girls were covered in the study.
Data was collected using a pre-tested standardized tool adopted from WHO Global School-based Student Survey [18]. Information on socio-demographic variables and behavioural NCD risk factors (tobacco use, alcohol use, physical activity and diet) was collected. To carry out this study, official permission was obtained in advance from the Principal/Head of Schools. A meeting of teachers and students was organized in each school, in order to explain the objectives and aims of study. In addition, teachers and students were explained about purpose of the study, ensuring them about the confidentiality of information and verbal consent was taken from students.

Data were analyzed using SPSS version 17.0. Bivariate analysis was done to determine the association between socio-demographic variables and tobacco and alcohol consumption. Multivariable logistic regression models were constructed relating the risk factors, i.e., dependent variables modeled individually; smoke cigarette/bidi, chew tobacco and drink alcohol to the independent variables modeled simultaneously; demographic variables and behavioural risk factors.

\section{Results}

\subsection{Prevalence of Tobacco and Alcohol Use}

Prevalence of tobacco use in any form was higher compared to the use of alcohol. Use of tobacco among girl students was significantly lower compared to their counterparts; $13 \%$ of boys and $3 \%$ girls smoked cigarette/bidis and $12 \%$ of boys and $3 \%$ of girls chewed tobacco. The prevalence of smoking among school children was $5 \%$ in the current study which is lower than Global Youth Tobacco Survey which gave a prevalence of $8 \%$ in 2009 [13]. On the other hand, prevalence of alcohol use is higher among girls in comparison to the prevalence of tobacco use. It is alarming that $5 \%$ of girls reported to have used alcohol while $10 \%$ of boys reported the same (Figure 1).

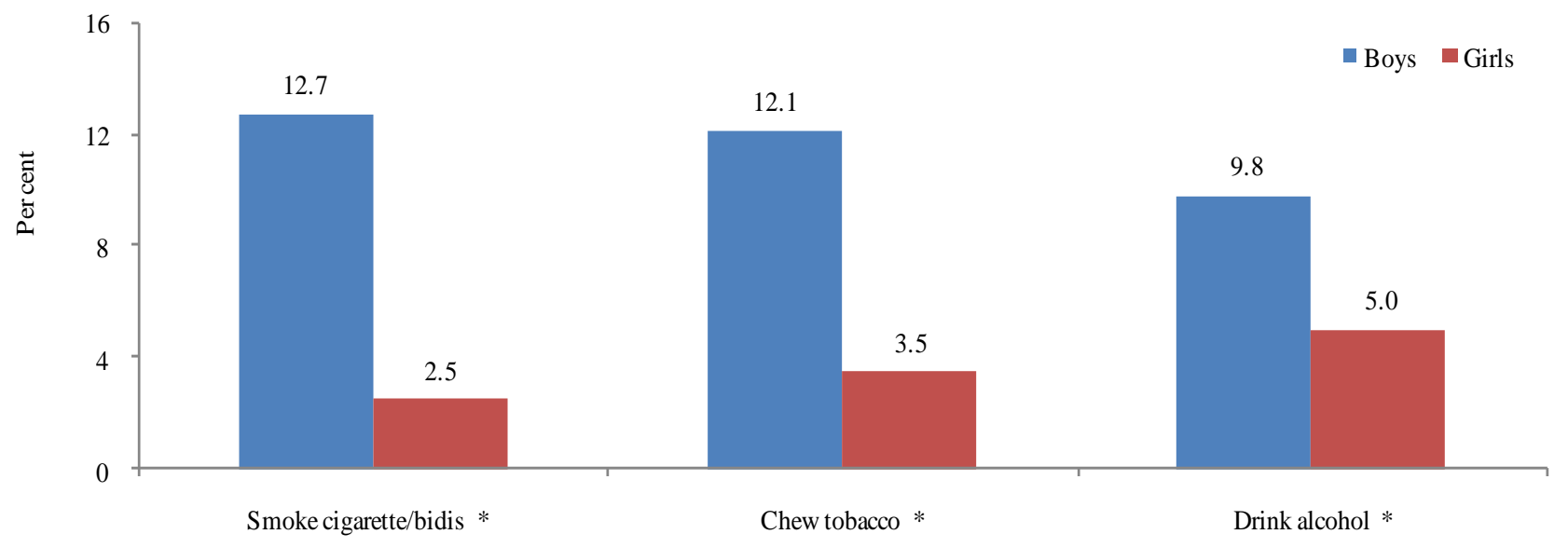

Figure 1. Prevalence of tobacco and alcohol use among students

*Prevalence of tobacco and alcohol use differs significantly among boys and girls ( $\mathrm{p}=0.001)$

-'n' is all respondents

Further investigation shows a surprising result that about one-third of students had first experienced tobacco use before the age of 10 years, showing easy access to cigarettes/bidis. The students try using tobacco mainly when they are aged 10-13 years. On the other hand, 6\% and $10 \%$ of students respectively reported to have smoked and chewed tobacco everyday, in the past 30 days. Further, $83 \%$ and $78 \%$ of students respectively reported to have used tobacco (chew and smoke respectively) for less than 9 days in the past 30 days. 


\subsection{Knowledge about Health Concerns and Use among Friends and Family Members}

Students were asked about the major health concerns of tobacco and alcohol use. Finding shows that students have good knowledge about the health concerns of tobacco use than the use of alcohol. Cancer has been stated as the prominent health concern of tobacco use while liver disease is stated for alcohol use. Students are also aware about other major health concern related to alcohol use including cancer followed by high blood pressure. However, 29\% of the students do not have knowledge about the health concerns of alcohol use while $22 \%$ of students do not have knowledge about the health concerns of cigarette smoking (Table 1).

Table 1. Knowledge about the health concerns of tobacco and alcohol use

\begin{tabular}{|c|c|c|c|}
\hline & $\begin{array}{c}\text { Smoke } \\
\text { cigarette }\end{array}$ & $\begin{array}{c}\text { Chew } \\
\text { tobacco }\end{array}$ & $\begin{array}{c}\text { Drink } \\
\text { alcohol }\end{array}$ \\
\hline Cancer & 68.4 & 79.6 & 25.7 \\
\hline $\begin{array}{l}\text { High Blood } \\
\text { Pressure }\end{array}$ & 7.1 & 4.0 & 9.0 \\
\hline Heart Diseases & 1.6 & 1.7 & 5.1 \\
\hline Diabetes & 0.6 & 0.8 & 1.1 \\
\hline Liver Diseases & -- & -- & 30.5 \\
\hline None of the above & 1.5 & 1.6 & 11.5 \\
\hline $\begin{array}{l}\text { I do not } \\
\text { know/Missing }\end{array}$ & 20.9 & 12.4 & 17.1 \\
\hline
\end{tabular}

Table 2 shows the use of tobacco and alcohol among the family members of the students. Finding shows that tobacco and alcohol use among parents/guardian is very high compared to siblings and friends. Around one-third of students reported that their family members, siblings or friends use tobacco while nearly two-fifth of students reported alcohol use.

Table 2. Drug use among family members and friends of the students

\begin{tabular}{|l|r|r|r|}
\hline & \multicolumn{1}{|c|}{$\begin{array}{c}\text { Smoke } \\
\text { cigarette }\end{array}$} & \multicolumn{1}{c|}{$\begin{array}{c}\text { Chew } \\
\text { tobacco }\end{array}$} & $\begin{array}{c}\text { Drink } \\
\text { alcohol }\end{array}$ \\
\hline No body & 50.1 & 58.9 & 55.2 \\
\hline Parents/guardian & 25.9 & 23.8 & 30.9 \\
\hline $\begin{array}{l}\text { Other household } \\
\text { members }\end{array}$ & 4.8 & 5.8 & 4.5 \\
\hline Siblings/Friends & 2.9 & 6.2 & 4.0 \\
\hline Don't know/missing & 16.3 & 5.4 & 5.4 \\
\hline
\end{tabular}

-'n' is all respondents

\subsection{Determinants of Tobacco and Alcohol Use}

Table 3 shows the likelihood of tobacco and alcohol use among students by different determining factors. Among the demographic factors, age is a prominent factor positively associated with tobacco and alcohol use. When compared to the students below age 13 years, cigarette smoking, chewing tobacco and drinking alcohol increases with age. When compared to boys, girl students are less likely to use tobacco while they are equally likely to use alcohol though this is statistically insignificant.

The knowledge factor about health concerns of using cigarette and alcohol does not have impact on its use among students, whereas, the students who are not aware of health concerns of chewing tobacco are more likely to chew tobacco at least once. Utilization among family members and siblings/friends has greater impact on smoking, chewing and alcohol use and these results are statistically significant. The likeliness of tobacco and alcohol use at least once is higher among students whose family members use it. When siblings/friends use it, the impact is such that the likelihood of students smoking is two times, and chewing tobacco and drinking alcohol three times as compared to the students whose family members or friends don't use tobacco or alcohol.

There is a strong association between smoking, chewing and drinking as these habits usually go together. In particular, tobacco use in both the forms goes hand-inhand. Finding shows that those students who chew tobacco has six times higher chance of smoking and vice versa. Smoking and alcohol use is also found to be a joint habit among students. The likelihood of smoking is five times higher among students who drink alcohol and vice versa. The likelihood of chewing is three times higher among the students who use alcohol and vice versa. These results are statistically significant even with $1 \%$ error margin.

Physical education in schools, physical exercise done by students and duration engrossed in watching television does not seems to have any impact on the use of tobacco and alcohol.

\section{Discussion and Recommendation}

Previous two Global Youth Tobacco Surveys had given estimates of prevalence of tobacco use in India [8]. However these surveys are tobacco specific and do not include other risk factors like alcohol consumption, unhealthy dietary practices, physical inactivity and obesity. There are some other studies conducted in limited settings which reflect patterns of risk factors such as physical activity and diet [15]. The current study was therefore undertaken to assess tobacco and alcohol use among school children that may lead to NCDs in selected districts located in different regions of India to not only get estimates of various risk factors in boys and girls but also to study other determinants analyzed in prior section.

Risk factors of NCD are evident among school students. The strong factors that emerge to be having impact on students to use tobacco and alcohol are age, awareness about harm, exposure among friends and family members, and watching television. It is clear that increase in age gives more exposure to students and thus increases their likelihood of tobacco and alcohol use and thereby likely increase risk of NCDs later in life. Current level of awareness about harmful effect of tobacco and alcohol has not shown any impact on its use among students. Also, the character of students is reflected by the character of their peers and thus likely to influences the use of tobacco and alcohol. Watching television has external effect which could be both positive and negative, the findings show that the duration engrossed in watching television has negative effect among students and influences them to use alcohol.

While education is a fundamental right for all, finding shows that schools have greater role in influencing and integrating education with health to shape the future population. The focus of adolescent education should be to sensitize the students about the environment in which they live, and role of family, siblings and friends on their lifestyle. This sensitization can possibly be undertaken by 
grassroots level networks of workers who can also help to sensitize out-of-school children and community members. Also, as the use of tobacco and alcohol go hand-in-hand among students, it is also clear that any intervention to stop the use of either tobacco or alcohol may lead to a compounded result in addressing NCDs.

Table 3. Factors determining the likelihood of tobacco and alcohol use among students

\begin{tabular}{|c|c|c|c|c|c|c|}
\hline \multirow[b]{2}{*}{ Factors } & \multicolumn{2}{|c|}{ Smoke cigarette/bidi } & \multicolumn{2}{|c|}{ Chew tobacco } & \multicolumn{2}{|c|}{ Drink alcohol } \\
\hline & $\begin{array}{l}\text { Odds } \\
\text { Ratio } \\
\end{array}$ & CI (95\%) & $\begin{array}{l}\text { Odds } \\
\text { Ratio } \\
\end{array}$ & CI (95\%) & $\begin{array}{l}\text { Odds } \\
\text { Ratio } \\
\end{array}$ & CI (95\%) \\
\hline \multicolumn{7}{|l|}{ Age } \\
\hline Below 13 yr & 1.000 & & 1.000 & & 1.000 & \\
\hline $14 \mathrm{yr}$ & 1.193 & $\begin{array}{c}(0.789- \\
1.804) \\
\end{array}$ & 1.162 & $\begin{array}{c}(0.806- \\
1.674) \\
\end{array}$ & 1.265 & $\begin{array}{c}(0.874- \\
1.830) \\
\end{array}$ \\
\hline $15 \mathrm{yr}$ & $1.763^{\mathrm{b}}$ & $\begin{array}{c}(1.180- \\
2.634)\end{array}$ & $1.434^{c}$ & $\begin{array}{c}(0.989- \\
2.079) \\
\end{array}$ & $2.043^{\mathrm{a}}$ & $\begin{array}{c}(1.417- \\
2.945)\end{array}$ \\
\hline $16 \mathrm{yr}$ and above & $2.813^{\mathrm{a}}$ & $\begin{array}{c}(1.747- \\
4.528)\end{array}$ & $2.197^{\mathrm{b}}$ & $\begin{array}{c}(1.391- \\
3.469) \\
\end{array}$ & $1.878^{\mathrm{c}}$ & $\begin{array}{c}(1.148- \\
3.070)\end{array}$ \\
\hline \multicolumn{7}{|l|}{ Sex } \\
\hline Boys & 1.000 & & 1.000 & & 1.000 & \\
\hline Girls & $0.266^{\mathrm{a}}$ & $\begin{array}{c}(0.176- \\
0.401)\end{array}$ & $0.508^{\mathrm{a}}$ & $\begin{array}{c}(0.364- \\
0.711)\end{array}$ & 1.001 & $\begin{array}{c}(0.734- \\
1.365) \\
\end{array}$ \\
\hline \multicolumn{7}{|c|}{$\begin{array}{llll}\text { Knowledge of disease } & \text { caused } & \text { by } \\
\text { smoking/chewing/drinking* }\end{array}$} \\
\hline Aware & 1.000 & & 1.000 & & 1.000 & \\
\hline Not aware & 0.986 & $\begin{array}{c}(0.646- \\
1.506) \\
\end{array}$ & $1.733^{\mathrm{b}}$ & $\begin{array}{c}(1.230- \\
2.443) \\
\end{array}$ & 0.890 & $\begin{array}{c}(0.657- \\
1.206) \\
\end{array}$ \\
\hline \multicolumn{7}{|c|}{ Use among family members/siblings/friends } \\
\hline None & 1.000 & & 1.000 & & 1.000 & \\
\hline Family members & $1.608^{\mathrm{b}}$ & $\begin{array}{c}(1.185- \\
2.183) \\
\end{array}$ & $1.962^{\mathrm{a}}$ & $\begin{array}{c}(1.473- \\
2.614) \\
\end{array}$ & $1.850^{\mathrm{a}}$ & $\begin{array}{l}(1.390- \\
2.462) \\
\end{array}$ \\
\hline Siblings/friends & $2.131^{\mathrm{c}}$ & $\begin{array}{c}\text { (1.166- } \\
3.898) \\
\end{array}$ & $3.502^{\mathrm{a}}$ & $\begin{array}{c}(2.038- \\
6.018) \\
\end{array}$ & $3.612^{\mathrm{a}}$ & $\begin{array}{c}(2.120- \\
6.154) \\
\end{array}$ \\
\hline \multicolumn{7}{|l|}{ Smoke cigarette/bidi } \\
\hline No & NA & & 1.000 & & 1.000 & \\
\hline Yes & & & $6.590^{\mathrm{a}}$ & $\begin{array}{c}(4.758- \\
9.127)\end{array}$ & $4.877^{\mathrm{a}}$ & $\begin{array}{c}(3.458- \\
6.880) \\
\end{array}$ \\
\hline \multicolumn{7}{|l|}{ Chew tobacco } \\
\hline No & 1.000 & & NA & & 1.000 & \\
\hline Yes & $6.575^{\mathrm{a}}$ & $\begin{array}{c}(4.770- \\
9.063)\end{array}$ & & & $3.148^{\mathrm{a}}$ & $\begin{array}{c}(2.234- \\
4.434)\end{array}$ \\
\hline \multicolumn{7}{|l|}{ Drink alcohol } \\
\hline No & 1.000 & & 1.000 & & NA & \\
\hline Yes & $5.085^{\mathrm{a}}$ & $\begin{array}{c}(3.628- \\
7.127)\end{array}$ & $3.066^{\mathrm{a}}$ & $\begin{array}{c}\text { (2.176- } \\
4.318)\end{array}$ & & \\
\hline \multicolumn{7}{|c|}{ Weekly physical education during current school year } \\
\hline Attended more than 4 days & 1.000 & & 1.000 & & 1.000 & \\
\hline Attended 1 to 3 days & $0.653^{\mathrm{c}}$ & $\begin{array}{c}(0.435- \\
0.982) \\
\end{array}$ & 1.191 & $\begin{array}{c}(0.803- \\
1.767) \\
\end{array}$ & 0.873 & $\begin{array}{c}(0.587- \\
1.298)\end{array}$ \\
\hline No class attended & 0.809 & $\begin{array}{c}(0.520- \\
1.259) \\
\end{array}$ & 0.723 & $\begin{array}{c}(0.460- \\
1.136) \\
\end{array}$ & 0.870 & $\begin{array}{c}(0.557- \\
1.357) \\
\end{array}$ \\
\hline \multicolumn{7}{|c|}{ Physical exercise done during past one week } \\
\hline Exercise more than 4 days & 1.000 & & 1.000 & & 1.000 & \\
\hline Exercise 1 to 3 days & 1.338 & $\begin{array}{c}(0.897- \\
1.995)\end{array}$ & 0.936 & $\begin{array}{c}(0.650- \\
1.350) \\
\end{array}$ & $1.389^{c}$ & $\begin{array}{l}(0.950- \\
2.030)\end{array}$ \\
\hline Did not exercise & 1.274 & $\begin{array}{c}(0.828- \\
1.958) \\
\end{array}$ & 0.915 & $\begin{array}{c}(0.615- \\
1.363) \\
\end{array}$ & 1.029 & $\begin{array}{c}(0.677- \\
1.565)\end{array}$ \\
\hline \multicolumn{7}{|l|}{ Duration of watching television } \\
\hline Less than 1 hr per day & 1.000 & & 1.000 & & 1.000 & \\
\hline 1 to $2 \mathrm{hr}$ per day & 0.898 & $\begin{array}{l}(0.633- \\
1.273)\end{array}$ & 1.238 & $\begin{array}{c}(0.886- \\
1.730)\end{array}$ & 1.190 & $\begin{array}{c}(0.848- \\
1.668)\end{array}$ \\
\hline 3 to $4 \mathrm{hr}$ per day & 1.161 & $\begin{array}{l}(0.758- \\
1.779)\end{array}$ & 1.379 & $\begin{array}{l}(0.915- \\
2.078)\end{array}$ & $1.517^{\mathrm{c}}$ & $\begin{array}{l}(1.008- \\
2.283)\end{array}$ \\
\hline More than $5 \mathrm{hr}$ per day & 0.907 & $\begin{array}{c}(0.528- \\
1.559) \\
\end{array}$ & 1.113 & $\begin{array}{c}(0.667- \\
1.857)\end{array}$ & $1.994^{\mathrm{b}}$ & $\begin{array}{c}(1.257- \\
3.162)\end{array}$ \\
\hline
\end{tabular}

${ }^{\text {a }}$ Significant at 99\%; Significant at 95\%; ' Significant at 90\%

*Knowledge of disease is about the respective dependent variables

Health education and knowledge about common risk factors of NCD need to be promoted among the higher secondary students. Innovative means of education about harms of tobacco and alcohol need to be identified. Training of teachers would be an important activity to promote healthy practices in schools. Students with high

risk profile should be closely monitored and provided specific counseling. Parental habits on tobacco and alcohol use may promote such habits in the youth. A broader and more comprehensive school based education strategy and a family based approach would be critical to prevent such unhealthy practices. Motivated students can 
become agents for promoting healthy lifestyles, not only among their peers but also members of the family. Policy and its implementation on restricting availability of tobacco and unhealthy diets in and around schools will be an important step to prevent incidence of NCDs.

\section{References}

[1] WHO. Global status report on non-communicable diseases, 2010.

[2] Srivastava RK, Bachani D. Burden of NCDs, Policies and Programs for Prevention and Control of Non-communicable Diseases in India. Indian J Community Medicine 2011 Dec; 36 (Supplement): S 7-13.

[3] Epping-Jordan JE, Galea G, Tukuitonga C, Beaglehole R. Preventing chronic diseases: taking stepwise action. Lancet 2005; 366: 1667-71.

[4] Government of India, Ministry of health \& Family Welfare National Programme for Prevention and Control of Cancer, Diabetes, Cardio-vascular Diseases (CVD) and Stroke (NPCDCS), 2010.

[5] Bonita R, de Courten M, Dwyer T, Jamrozik K, Winkelmann R. Surveillance of risk factors for noncommunicable diseases: The WHO STEP wise approach. Geneva, Switzerland: World Health Organization; 2002.

[6] Ng N, Stenlund H, Bonita R, Hakimi M, Wall S, Weinehall L. Preventable risk factors for noncommunicable diseases in rural Indonesia: prevalence study using WHO STEPS approach. Bull World Health Organ 2006; 84: 305-13.

[7] Hoang VM, Byass P, Dao LH, Nguyen TK, Wall S. Risk factors for chronic disease among rural Vietnamese adults and the association of these factors with sociodemographic variables: findings from the WHO STEPS survey in rural Vietnam, 2005. Prev Chronic Dis 2007; 4: A 22.

[8] Singh V, Pal HR, Mehta M, Dwivedi SN, Kapil U. Pattern of Tobacco Use Among School Children in National Capital
Territory (NCT). Indian J Pediatrics 2007 Nov; 74 (11): 10131020.

[9] Narain R, Sardana S, Gupta S, Sehgal A. Age at initiation \& prevalence of tobacco use among school children in Noida, India: A cross-sectional questionnaire based survey. Indian J Med Res 2011 March; 133: 300-307.

[10] Ningombam S, Hutin Y, MurhekarMV. Prevalence and pattern of substance use among the higher secondary school students of Imphal, Manipur. Natl Med J India 2011; 24: 11-15.

[11] Singh V, Gupta R. Prevalence of Tobacco Use and Awareness of Risks among School Children in Jaipur. JAPI 2006 August; 54: 609-612.

[12] George A, Varghese C, Sankarnarayanan R, Nair MK. Use of tobacco and alcoholic beverages by children and teenagers in a low-income coastal community on South India. J Cancer Educ 1994; 9:111-13.

[13] WHO, Global Youth Tobacco Survey-India 2000-2004; Chapter 3 Tobacco Use in India: Practices, Patterns and Prevalence: 43-73.

[14] Tsering D, Pal R, Dasgupta A. Licit and illicit substance use by adolescent students in eastern India: Prevalence and associated risk factors. J Neurosci Rural Pract. 2010 Jul-Dec; 1 (2): 76-81.

[15] Chopra A, Dhawan A, Sethi H, Mohan D. Association between parental and offspring's alcohol use-population data from India. J Indian Assoc Child Adolescent Health 2008; 4 (2): 38-43.

[16] Government of India, Ministry of Health and Family Welfare. Integrated Disease Surveillance Project, 2006. http://idsp.nic.in/.

[17] World Health Organization. Global School-based Student Health Survey: India (CBSE) 2007 fact sheet. http://www.who.int/chp/gshs/india/en/index.html.

[18] World Health Organization. Global School-based Student Health Survey (GSHS): 2006 India, central board of secondary education (CBSE) GSHS questionnaire. http://www.who.int/chp/gshs/india/en/index.html.

[19] Bachani D, Sogarwal R, Shukla SK, Shelat T and Gupta S. Dietary Practices and Physical Activity Performed by Adolescent in Selected Districts of India. Indian Journal of Community Health 2013 April-June; Vol. 25 (2): 171-77. 